author, date, title, journal, series, volume, page. The committee advocates giving the year number in full, since zoology at any rate neither began nor ended with the nineteenth century. If this be done and a logical order followed, both I825, I0, 6 , and 6 , I0, I 825 are equally intelligible, though personally I prefer 'Oct.' to ' Io' or ' $\mathrm{X}$.' The intercalation of the date between volume and page-numbers is illogical and often misleading.

$$
\text { F. A. BAther, }
$$

Sec. B.A. Committee Zool. Bibl.

March 20.

I THOUGHT that this pernicious custom had long ago disappeared for ever. Any one who has occasion to refer to the long series of papers on the Nomenclature of the Foraminifera in the Am. Mag. Nat. Hist., I $859-72$, will cordially endorse Dr. Rastall (Nature, March 20, p. 4I8). References to these in synonymies are made indifferently to the journal and its reprints, and it is never safe to rely upon them.

There exists, however, a far more ghastly crime than the mere re-pagination of reprints. One looks with suspicion on a page reference (say I-20), but one is tempted to accept as 'original' page references (say) roo et seq. But the late Charles Schlumberger used to have his reprints paged consecutively-and left out his own pagination when he was not allowed to do so, and took it up again when he was. The awful result was as follows. His first paper was re-paged I-3; his second was not re-paged, and he allowed for this in his third, which was re-paged ro-I9 with a second part paged 20-23, and he allowed for his new title wrappers, so his next was re-paged $27-34$, the next $35-37$, the next $39-89$, and so it went on until 1894, when he had reached pp. 237-243, an unre-paged reprint, which had its original pagination II8-123, coming between pp. 222 and 237. After this, probably yielding to infuriated pressure, he abandoned the system, but the mischief was done, and no page reference to any of his twenty-one papers (up to 1894) is to be accepted without reference to the original journal.

It would be interesting to know whether any other writer ever committed this outrage upon posterity. EDWARD HERON-ALLEN.

\section{The Evolution of Rosa.}

THE recently published paper of Dr. C. C. Hurst " Experiments in Genetics," 38, 1925) on the chromosomes and characters in Rosa may well mark a new epoch in biology. We must await the appearance of his monograph for full details, but as he suggests, we may in the meanwhile try to apply the "Rosa principles' to other plants and animals. It is suggested that the common ancestor of all roses was a northern decaploid species, at present unknown. The various forms could have arisen by the dropping out of sets of chromosomes, the existing five diploid types being the end-products of this process. We are told, however, that " certain cultivated triploid and tetraploid forms are obviously duplicated forms which have arisen ... by duplication of the septets of chromosomes." These maintain the essential specific characters of the original diploid species, instead of showing a complex of the characters of diverse septets. Is it not possible to suppose that this duplication may have been the first step in the production of polyploid species, the latter acquiring the diverse septet characters by successive mutations? The Drosophila work has shown that mutations are likely to be lethal or unfavourable. In a diploid species such mutations should apparently work more havoc than in a polyploid one. Polyploidy might then be a condition favouring the survival and accumulation of mutated genes, resulting after very long periods of time in diversity of the septets. Such diversity might come to have its advantages, as Dr. Hurst indicates, in specific cases. On the other hand, in some cases the shedding of a septet might be advantageous, getting rid of some undesirable features, and producing a more uniform or consistent type. Thus the diploid R. rugosa, which I found to be a strictly sea-coast plant in Siberia, is a well-defined type specially adapted to its peculiar habitats but not extending even a few miles inland. Yet it is not to be expected that the diploids will all be successful, and close field study combined with cytological research may be expected to reveal a variety of forms with reduced chromosome numbers, coming into existence only to perish at once or in a few years. Many, probably, may not even be capable of development.

Possibly, then, there is a double process going on, and it may not appear certain that the original rose was decaploid, though the existing diploids may all be derived from polyploid ancestors. There has been time for much to happen, for we know from the Miocene of Florissant several species of roses extraordinarily like those of the present day (cf. Fig. I).

University of Colorado, March 4

\section{T. D. A. Cockerell.}

\section{The Banana in America.}

As a student of culture-history I must protest against the inferences drawn by Dr. E. W. Berry from the finding of fossil banana seeds in Tertiary beds in Colombia which were referred to in NATURE, February 6, I926, p. 209.

The moot-problem resolves itself into two questions. What is the value of the early references to the banana as a plant cultivated by the natives prior to the possible introduction of the cultivated banana? And, what follows from the indigenousness of the wild banana as to its cultivation by the aborigines? The 'historical evidence' for the pre-Colombian cultivation of the banana is considered quite unconvincing by such authorities as Baron Erland Nordenskiöld, who writes : "It may be regarded as proved by De Candolle and Karl v. d. Steinen that the banana was introduced into America by the whites" ("Comparative Ethnographical Studies," vol. 5, r922, $64 s q$.$) . On the other hand, the conclusion that if$ the banana was indigenous in America it must have been cultivated by the natives is a monstrous non sequitur that might be labelled a typical 'botanist's fallacy,' were the sobriquet not unjust to many botanists keenly alive to the historical questions involved in the history of cultivation. This methodological question has been so adequately treated in Dr. B. Laufer's "Sino-Iranica" (Chicago, I9I9), that I will here content myself with a reference to that treasure-trove of information. It no more follows that, say, the Peruvians would cultivate a wild plant

$$
\text { NO. 2945, VOL. I I } 7 \text { ] }
$$

